\title{
Evaluating the safety and efficacy of axitinib in the treatment of advanced renal cell carcinoma
}

\author{
This article was published in the following Dove Press journal: \\ Cancer Management and Research \\ II February 2015 \\ Number of times this article has been viewed
}

\author{
Orvar Gunnarsson' \\ Nicklas R Pfanzelter ${ }^{2}$ \\ Roger B Cohen' \\ Stephen M Keefe' \\ 'Department of Medicine, Division of \\ Hematology and Oncology, Hospital \\ of the University of Pennsylvania, \\ Philadelphia, PA, ${ }^{2}$ Department of \\ Medicine, Division of Hematology and \\ Oncology, Rush University Medical \\ Center, Chicago, IL, USA
}

Correspondence: Orvar Gunnarsson Hospital of the University of Pennsylvania, 3400 Spruce Street, 16 Penn Tower, Philadelphia, PA, 19104, USA

$\mathrm{Tel}+\mathrm{I} 2156623681$

Fax +I 2156153704

Email orvar.gunnarsson@uphs.upenn.edu

\begin{abstract}
Axitinib is a tyrosine kinase inhibitor of vascular endothelial growth factor receptor, platelet-derived growth factor receptor- $\alpha$, and c-kit. Phase I studies demonstrated $5 \mathrm{mg}$ twice daily as the recommended starting dose with notable effects seen in renal cell carcinoma, an observation confirmed in Phase II trials. The trial of comparative effectivess of axitinib versus sorafenib in advanced renal cell carcinoma (AXIS) was an international randomized Phase III study designed for registration purposes, compared axitinib to sunitinib. This trial randomized 723 patients with metastatic kidney cancer to axitinib or sunitinib in the second-line setting and demonstrated a median progression-free survival of 6.7 months for axitinib versus 4.7 months for sorafenib $(P<0.0001)$. Clinical benefit was detected regardless of prior therapy, but no overall survival benefit has been observed. Axitinib is well tolerated without a significant effect on quality of life. The most common grade 3 toxicities are hypertension (16\%), diarrhea $(11 \%)$, and fatigue $(11 \%)$, with other notable side effects being anorexia, nausea, hand-foot syndrome, and rash. Patients who developed diastolic blood pressure $>90 \mathrm{mmHg}$ were noted to have significantly longer median overall survival and overall response rates when compared to normotensive patients. Therefore, the manufacturer recommends escalating the twice-daily dose to $7 \mathrm{mg}$ and $10 \mathrm{mg}$, as tolerated, if there is no significant increase in blood pressure on treatment. Currently, axitinib is approved for use in the second-line setting for patients with metastatic renal cell carcinoma. Research is ongoing in other disease settings.
\end{abstract}

Keywords: axitinib, renal cell carcinoma, side effects, drug safety

\section{Review of pharmacology, mode of action, pharmacokinetics of axitinib}

Axitinib is a substituted indazole derivative that potently inhibits all known vascular endothelial growth factor (VEGF) receptors (VEGFRs) at subnanomolar concentrations, and is able to inhibit platelet-derived growth factor receptor (PDGFR)- $\alpha$ and c-kit at nanomolar concentrations. ${ }^{1}$ In vitro, axitinib inhibits the VEGF signaling axis by preventing autophosphorylation in endothelial cells (ECs) leading to the inhibition of EC growth, survival, and proliferation.

The dramatic effect of axitinib on ECs has been demonstrated in preclinical studies. When axitinib was applied to a spontaneous islet cell tumor model of RIPTag2 transgenic mice, endothelial fenestrations disappeared, blood flow decreased, and new vessel sprouting was significantly diminished within 24 hours. Existing vascular density was reduced by almost $80 \%$ after 7 days, and there was significantly less expression of VEGFR-2 and VEGFR-3. The remaining vessels demonstrated ghost-like basement membranes that persisted after a loss of ECs, consistent with 
other models of vascular regression. When the experiment was extended to 21 days, investigators observed a significant concordant reduction in tumor mass. ${ }^{2}$

Axitinib was initially evaluated in vivo in mice containing human renal cell carcinoma (RCC), melanoma, and colorectal cancer xenografts, and it inhibited tumor growth in a dose-dependent fashion for all three histologies. The investigators observed that the tumors with the most dramatic effects had the greatest reduction in CD31 staining, a marker expressed on ECs, suggesting activity through a reduction in microvessel density. ${ }^{3}$

Axitinib is considerably more potent than the other available VEGFR tyrosine kinase inhibitors (TKIs). The inhibitory concentration $\left(\mathrm{IC}_{50}\right)$ of axitinib is at least 100 times lower than that of sorafenib, sunitinib, or pazopanib for VEGFR1, VEGFR2, and VEGFR3, ${ }^{3-6}$ and at least as potent at inhibiting PDGFR- $\alpha$, PDGFR- $\beta$, and c-kit. Axitinib appears to be considerably more selective for the VEGFR1-3 targets than for PDGFR, c-kit, and FLT3. It has almost no affinity for FLT3 and RET, unlike sunitinib and sorafenib. ${ }^{3-6}$

Based on these promising preclinical results, a multicenter Phase I study of axitinib was conducted, enrolling 36 patients with advanced solid tumors. ${ }^{1}$ Six of those enrolled had metastatic RCC. Axitinib was dosed orally twice daily at doses between $5 \mathrm{mg}$ and $30 \mathrm{mg}$. Hypertension was the most common dose-limiting toxicity (eleven patients experienced grade 3-4 toxicity, of which most were manageable with antihypertensive medications), while stomatitis, increased liver enzymes, and seizures occurred in two patients in each category. Five patients died while in the study, of whom three patients were considered to have died from disease progression. The remaining two patients had lung adenocarcinoma and developed fatal hemoptysis - one had a large centrally located tumor that bled while on treatment; the second developed grade 1 hemoptysis and was taken off study and then, some weeks later, developed disease progression and infection complicated by grade 4 hemoptysis. Following these events, the protocol was amended to exclude patients with centrally located lung tumors, as well as patients with squamous cell carcinoma of the lung, No subsequent episodes of hemoptysis have been reported.

The maximum tolerated dose was determined to be $5 \mathrm{mg}$ twice daily, and axitinib was rapidly absorbed, reaching peak plasma concentrations after 2-6 hours of administration. Steady state was reached in 15 days with a terminal plasma half-life of 2-5 hours. ${ }^{1}$ Later work determined that axitinib is predominantly protein bound $(>99 \%)$, primarily to albumin, but also to $\alpha$-1-acid glycoprotein. ${ }^{7}$ Pharmacokinetics analysis revealed that median plasma exposure was $49 \%$ higher in fasting subjects. The oral dose of $5 \mathrm{mg}$ twice daily in the fasting state was recommended for Phase II dosing. In the Phase I evaluation, two of the six patients with RCC had an objective partial response (PR), foreshadowing the drug's activity in this disease. ${ }^{1}$

\section{Efficacy studies}

Two Phase II studies followed, confirming the antineoplastic activity for axitinib in RCC. The first study enrolled 52 patients who had failed cytokine therapy. ${ }^{8}$ Patients were excluded if they had received other VEGF-targeted therapy or if they had uncontrolled hypertension. All patients but three had undergone a prior nephrectomy. Thirty patients (58\%) had at least one Memorial Sloan Kettering Cancer Center (MSKCC) adverse risk factor. ${ }^{9}$ All patients were treated with axitinib $5 \mathrm{mg}$ twice daily in the fasting state, and therapy continued until unacceptable toxicity or progression. The study's overall response rate (ORR) was 44.2\% (95\% confidence interval [CI]: 30.5-58.7), with two complete responses (CRs) and 21 PRs. An additional 13 patients had stable disease (SD) for more than 24 weeks, and nine had SD for more than 8 weeks, translating into an overall clinical benefit rate of $87 \%$. Most responding patients had clear cell RCC. One patient had nonclear cell histology (papillary) and was determined to have SD with treatment.

Secondary endpoints included duration of response, time to progression, survival, quality of life, and safety. For those with $\mathrm{CR}$ or $\mathrm{PR}$, the median response duration was 23.0 months (95\% CI: 20.9 - not estimable; range: 4.2-29.8). The median time to progression for the study cohort was 15.7 months (95\% CI: 8.4-23.4; range: 0.03-31.5) and median overall survival (OS) was 29.9 months (95\% CI: 20.3 - not estimable; range: $2.4-35.8$ months). The median duration of treatment was 9.4 months (range: $0.1-32.0$ months). The ORR and response duration reported for axitinib compared favorably to Phase II studies of other similar TKIs. ${ }^{10,11}$ As with other single-arm Phase II studies, results may have been especially favorable due to subject selection bias, reflected in the observation that $42 \%$ of the patients had no MSKCC unfavorable risk factor. Nevertheless, this study demonstrated the potential for therapeutic efficacy with axitinib in the treatment of patients with metastatic RCC. Notably, a recent update of these data reported a 5-year survival rate of $20.6 \%$ $(10.9 \%-32.4 \%)$ after a median follow up of 5.9 years. ${ }^{12}$

The second Phase II study evaluated the activity of axitinib in patients previously treated with VEGF-targeted TKIs. Investigators enrolled patients with metastatic RCC who had 
progressive disease on treatment with sorafenib. ${ }^{13}$ This openlabel, multicenter study enrolled 62 patients. Axitinib was given as $5 \mathrm{mg}$ twice daily, with a provision for dose escalation to $10 \mathrm{mg}$ twice daily in the absence of greater than grade 2 adverse effects, and in patients with no significant increase in blood pressure or hypertension, with a protocol amendment later introduced to prohibit dose escalation in patients receiving antihypertensive medications. Subjects were required to have received sorafenib, but they could have had other therapies as well; $74.2 \%$ of patients had received two or more lines of any systemic therapy prior to entry, and $22.6 \%$ of the cohort had received sunitinib in addition to sorafenib. This trial mainly enrolled patients with clear cell RCC. Only three subjects had nonclear cell histologies. All 62 subjects had had a prior nephrectomy. Fourteen patients experienced a PR for an ORR of $22.6 \%$ (95\% CI: $12.9 \%-35.0 \%)$, and an additional eleven patients (17.7\%) achieved SD. Approximately half of the patients (33 of 62) had their axitinib dose escalated to $>5 \mathrm{mg}$ twice daily, but the observed response rates did not differ by axitinib dose. Most $(80 \%)$ of the evaluable patients demonstrated some degree of target lesion regression. The median duration of response was 17.5 months (95\% CI: 7.4 - not estimable). The median progression-free survival (PFS) was 7.4 months (95\% CI: 6.7-11.0) and the median OS was 13.6 months (range: $8.4-18.8$ months) from the start of axitinib therapy. This Phase II study established the activity of axitinib in patients with clear cell RCC refractory to conventional VEGF-inhibitor therapy. PRs were seen in $26.7 \%$ of patients with one prior antiangiogenic therapy, and in $7.1 \%$ of patients who had received both sunitinib and sorafenib. The median number of prior therapies was two. Not surprisingly, response rates were lower in this study, ${ }^{13}$ when compared to the results in a population that had only received prior cytokine therapy. ${ }^{8}$ The authors hypothesized that axitinib's efficacy in the second- and third-line setting after prior TKIs might have been due to axitinib's high potency and high selectivity for VEGFR1, VEGFR2, and VEGFR3.

Following two successful Phase II studies, a large, international, multicenter, randomized Phase III study was designed for registration purposes (The trial of comparative effectivess of axitinib versus sorafenib in advanced renal cell carcinoma). Referred to as the AXIS study, ${ }^{14}$ it compared the effectiveness of axitinib versus sorafenib in advanced RCC in the second-line RCC setting. The investigators enrolled 723 patients with metastatic clear cell RCC from 22 countries who had initially received sunitinib (54\%), bevacizumab plus interferon- $\alpha(8 \%)$, temsirolimus $(3 \%)$, or cytokine therapy $(35 \%)$. The median age of the study participants was 61 years (range: 20-82 years), and all had an Eastern Cooperative Oncology Group performance status of 0 or 1 . MSKCC risk stratification identified $28 \%$ of the patients as favorable risk, $37 \%$ as intermediate risk, and $33 \%$ as poor risk. Patients were randomized $1: 1$ to either sorafenib $400 \mathrm{mg}$ twice daily or axitinib $5 \mathrm{mg}$ twice daily. Randomization was stratified by performance status and by the type of first-line therapy. Axitinib dosing was titrated to $7 \mathrm{mg}$ twice daily, and then to $10 \mathrm{mg}$ twice daily in the absence of greater than grade 2 toxicity for 2 weeks, if their blood pressure was $<150 / 90$ $\mathrm{mmHg}$ and if the patient was not on antihypertensive medication. The primary endpoint was PFS, as assessed by a blinded independent review.

The trial demonstrated a statistically significant improvement in PFS for axitinib as compared with sorafenib (hazard ratio $[\mathrm{HR}]=0.67 ; 95 \% \mathrm{CI}: 0.54-0.81 ; P<0.0001, \log -$ rank test). ${ }^{14}$ The median PFS was 6.7 months for patients treated with axitinib and 4.7 months for those randomized to sorafenib. Axitinib conferred clinical benefit in terms of PFS to patients regardless of prior therapy such as sunitinib (4.8 months versus 3.4 months, respectively; $P=0.0107$ ) or prior cytokine therapy (12.5 months versus 6.5 months, respectively; $P<0.0001)$. Similar findings were observed after further segregating the groups by the specific cytokine therapies they had received previously. There were no CRs, but the PR rate was $19 \%$ for axitinib and $9 \%$ for sorafenib $(P=0.0001)$, and the median duration of response was 11 months (95\% CI: 7.4 - not estimable) for axitinib and 10.6 months (95\% CI: 8.8-11.5) for sorafenib. No difference was observed between treatment arms in terms of OS. Based on the statistically significant increase in PFS seen for axitinib, on January 27, 2012, the United States Food and Drug Administration approved axitinib for the treatment of metastatic RCC after one prior systemic therapy, and other regulatory agencies followed suit (see Table 1 for a review on US FDA (Food and Drug Administration)-approved VEGF inhibitors for RCC). It is important to emphasize that given no observed difference in OS between axitinib and sorafenib, the overall benefit compared to sorafenib appears modest in the postsunitinib setting. ${ }^{15}$

The updated results from the AXIS trial were reported in the spring of $2013^{16}$ and showed that axitinib was associated with a median PFS of 8.3 months, as compared to 5.7 months for sorafenib $(\mathrm{HR}=0.66$; 95\% CI: 0.55-0.78; one-sided $P<0.0001)$ and a median OS of 20.1 months for axitinib compared to 19.2 months for sorafenib ( $\mathrm{HR}=0.97 ; 95 \% \mathrm{CI}$ : $0.80-1.17$; one-sided $P=0.3744$ ). The fact that there was no significant survival advantage is perhaps not surprising given 
Table I Overview of United States Food and Drug Administration-approved therapies for RCC and corresponding angiogenesis inhibitor trials

\begin{tabular}{|c|c|c|c|c|c|c|c|}
\hline \multirow[t]{2}{*}{ Drug } & \multirow{2}{*}{$\begin{array}{l}\text { Patients } \\
\text { (n) }\end{array}$} & \multirow{2}{*}{$\begin{array}{l}\text { Treatment } \\
\text { arms }\end{array}$} & \multirow{2}{*}{$\begin{array}{l}\text { Phase } \\
\text { Line of treatment }\end{array}$} & \multicolumn{2}{|l|}{ PFS } & \multicolumn{2}{|l|}{ os } \\
\hline & & & & Median (months) & HR (95\% Cl) & Median (months) & HR $(95 \% \mathrm{Cl})$ \\
\hline \multicolumn{8}{|l|}{ Bev } \\
\hline Escudier & 327 & $\mathrm{Bev}+\mathrm{IFN} \alpha$ & III & 10.4 & 0.57 & 23.3 & 0.86 \\
\hline \multirow[t]{2}{*}{ et $\mathrm{al}^{35-37}$} & 322 & versus placebo + & First line & 5.5 & $(0.45-0.72)$ & 21.3 & $(0.72-1.04)$ \\
\hline & & $\mathrm{IFN} \alpha$ & & & $P<0.0001$ & & $P=0.1291$ \\
\hline \multirow[t]{3}{*}{ Rini et al $\left.\right|^{38,39}$} & 369 & $\mathrm{Bev}+\mathrm{IFN} \alpha$ & III & 8.5 & 0.71 & 18.3 & 0.86 \\
\hline & 363 & versus IFN $\alpha$ & First line & 5.2 & $(0.6 \mathrm{I}-0.83)$ & 17.4 & $(0.73-1.01)$ \\
\hline & & & & & $P<0.0001$ & & $P=0.069$ \\
\hline \multicolumn{8}{|l|}{ Tem } \\
\hline Hudes & 209 & Tem versus & III & 3.8 & HR not reported & 10.9 & Tem: \\
\hline \multirow[t]{7}{*}{ et $\mathrm{al}^{40}$} & 210 & Tem + IFN $\alpha$ & First line & 3.7 & Tem versus & 8.4 & 0.73 \\
\hline & 207 & versus IFN $\alpha$ & & 1.9 & IFN $\alpha$ significantly & 7.3 & $(0.58-0.92)$ \\
\hline & & & & & different & & $P=0.008$ \\
\hline & & & & & $(P<0.00 \mathrm{I})$ & & Tem + IFN $\alpha:$ \\
\hline & & & & & & & 0.96 \\
\hline & & & & & & & $(0.76-1.20)$ \\
\hline & & & & & & & $P=0.70$ \\
\hline \multicolumn{8}{|l|}{ Everolimus } \\
\hline Motzer & 277 & Everolimus & III & 4.9 & 0.33 & 14.8 & 0.87 \\
\hline \multirow{2}{*}{ et $\mathrm{al}^{41,42}$} & 139 & versus placebo & Second or later line & 1.9 & $(0.25-0.43)$ & 14.4 & $(0.65-1.17)$ \\
\hline & & & of therapy & & $P<0.001$ & & $P=0.162$ \\
\hline \multicolumn{8}{|l|}{ Sorafenib } \\
\hline Escudier & 451 & Sorafenib & III & 5.5 & 0.44 & 17.8 & 0.88 \\
\hline \multirow[t]{2}{*}{ et $\mathrm{al}^{43,44}$} & 452 & versus placebo & Second or later line & 2.8 & $(0.35-0.55)$ & 15.2 & $(0.74-1.04)$ \\
\hline & & & of therapy & & $P<0.000001$ & & $P=0.146$ \\
\hline \multicolumn{8}{|l|}{ Sunitinib } \\
\hline Motzer & 375 & Sunitinib & III & 11 & 0.54 & 26.4 & 0.82 \\
\hline \multirow[t]{2}{*}{ et $\mathrm{al}^{45,46}$} & 375 & versus IFN $\alpha$ & First line & 5 & $(0.45-0.64)$ & 21.8 & $(0.67-1.00)$ \\
\hline & & & & & $P<0.001$ & & $P=0.05 \mathrm{I}$ \\
\hline \multicolumn{8}{|l|}{ Pazopanib } \\
\hline Sternberg & 290 & Pazopanib & III & All patients: & 0.46 & All patients: & 0.91 \\
\hline \multirow[t]{8}{*}{ et $\mathrm{al}^{47,48}$} & 145 & versus placebo & First or second line & 9.2 & $(0.34-0.62)$ & 22.9 & $(0.7 I-I .16)$ \\
\hline & & & & 4.2 & $P<0.000$ I & 20.5 & $P=0.224$ \\
\hline & & & & First line: & 0.40 & First line: & 1.01 \\
\hline & & & & 11.1 & $(0.27-0.60)$ & 22.9 & $(0.72-1.42)$ \\
\hline & & & & 2.8 & $P<0.0001$ & 23.5 & NR \\
\hline & & & & Cytokine pretreated: & 0.54 & 22.7 & 0.82 \\
\hline & & & & 7.4 & $(0.35-0.84)$ & 18.7 & $(0.57-1.16)$ \\
\hline & & & & 4.2 & $P<0.00$ I & & NR \\
\hline \multicolumn{8}{|l|}{ Axitinib } \\
\hline \multirow[t]{3}{*}{ Motzer et $\mathrm{a}^{16}$} & 361 & Axitinib versus & III & 8.3 & 0.66 & 20.1 & 0.97 \\
\hline & 362 & sorafenib & Second or later line & 5.3 & $(0.55-0.78)$ & 19.2 & $(0.80-1.17)$ \\
\hline & & & of therapy & & $P<0.000$ I & & $P=0.3744$ \\
\hline
\end{tabular}

Abbreviations: RCC, renal cell carcinoma; n, number; PFS, progression-free survival; HR, hazard ratio; Cl, confidence interval; OS, overall survival; Bev, bevacizumab; IFN $\alpha$, interferon-alpha; Tem, temsirolimus; NR, not reported.

that $54 \%$ of the axitinib group and $57 \%$ of the sorafenib group received additional therapy, and that $23 \%$ and $25 \%$ of each drug group, respectively, went on to receive two or more subsequent treatments. The availability of multiple salvage therapies may limit the ability to interpret the efficacy of drugs in this setting. ${ }^{17}$

Axitinib has also been evaluated in the first-line setting in metastatic RCC. A multicenter trial randomized patients with treatment-naïve metastatic clear cell RCC, measurable disease, and an Eastern Cooperative Oncology Group PS of 0 or 1 to either axitinib $5 \mathrm{mg}$ twice daily or sorafenib $400 \mathrm{mg}$ twice daily (2:1 randomization).$^{18}$ This trial enrolled 288 patients, primarily from outside the US, with 153 patients coming from the Ukraine, Russia, and India. The patients were well balanced for demographic and clinical variables, such as age (median age: 58 years in both groups), MSKCC 
favorable risk status (49\% in the axitinib group versus 55\% in the sorafenib group), and prior nephrectomy ( $85 \%$ in the axitinib group versus $90 \%$ in the sorafenib group). No statistically significant difference was observed between treatment groups in terms of the primary endpoint; the median PFS was 10.1 months for axitinib and 6.5 months for sorafenib (HR $=0.77$; 95\% CI: 0.56-1.05). The objective response rate was significantly higher with axitinib than sorafenib: $32 \%$ versus $15 \%$, respectively (one-sided $P=0.0006$ ).

Finally, axitinib has been studied in the neoadjuvant setting. A single-institution Phase II trial ${ }^{19}$ evaluated the efficacy of axitinib in terms of downsizing tumors in 24 patients with biopsy-proven clear cell RCC. The study protocol planned for treatment with axitinib for 12 weeks prior to surgery. Twenty-two patients completed therapy as planned, with one patient undergoing surgery after 11 weeks and one patient stopping therapy after 7 weeks due to acute kidney injury and taken to surgery at that time, earlier than anticipated. Notably, $100 \%$ of evaluable patients (number [n] =23) showed tumor shrinkage with a median reduction in tumor diameter of $28.3 \%$, and a $45.8 \%$ PR $(n=24)$. All patients had their axitinib dose up-titrated during therapy with a side effect profile similar to that seen in other studies. ${ }^{19}$

\section{Dose titration}

Similar to other therapies that inhibit VEGF-VEGFR signaling, axitinib induces hypertension, which appears to be a biomarker for drug activity. ${ }^{20}$ In both Phase II studies described earlier, ${ }^{8,13}$ patients that developed a diastolic blood pressure (DBP) $>90 \mathrm{mmHg}$ were noted to have significantly longer median OS and ORR when compared to those without elevated DBP (30 months versus 9.8 months, respectively; $50.8 \%$ versus $10.2 \%$, respectively). ${ }^{21}$ Similar results were seen in a pooled analysis of data from three Phase II studies of 178 patients with metastatic RCC. ${ }^{22}$ According to that analysis, the median PFS was 14.6 months for patients with elevated DBP compared with 7.86 months for patients without elevated DBP (HR $=0.590$; 95\% CI: 0.402-0.866). The median OS for the same comparison was 29.5 months, as compared with 18.5 months ( $\mathrm{HR}=0.622$; 95\% CI: 0.411-0.942). Another recent pooled analysis included two Phase II trials in RCC, as well as three other single-agent axitinib Phase II studies in other tumor types. Among 238 patients in the analysis, those with at least one recorded elevated DBP level had a significantly lower risk of death $(\mathrm{HR}=0.55 ; P<0.001)$ and significantly greater ORRs ( $43.9 \%$ versus $12.0 \%$; $P<0.001) .{ }^{20}$ Interestingly, in a recent meta-analysis, ${ }^{23}$ axitinib was found to be more likely to cause hypertension (40.1\%) than sorafenib
(23.4\%; $P<0.0001)$, sunitinib $(21.6 \% ; P<0.0001)$, pazopanib $(35.5 \% ; P=0.34)$, and vandetanib $(24.2 \% ; P<0.0001) .{ }^{23}$

One hypothesis to explain the finding of varying degrees of blood pressure response to axitinib treatment is that patients who do not develop hypertension may not have sufficient plasma exposure to axitinib. A retrospective analysis of 590 subjects who received axitinib in a total of 17 trials was performed, ${ }^{22}$ which included 181 patients with metastatic RCC. This trial found, by logistic regression, a significant $(P<0.0001)$ relationship between axitinib plasma exposure and the probability of a response (ie, a 1.5-fold increase in the probability of achieving a PR for every $100 \mathrm{~h} \times \mathrm{ng} / \mathrm{mL}$ increase in the area under the curve [AUC]). They also explored the relationship between AUC and clinical endpoints such as PFS and OS. By stratifying the patients into groups of AUC greater than or equal to the axitinib total daily therapeutic exposure of $300 \mathrm{~h} \times \mathrm{ng} / \mathrm{mL}$ (high AUC) or $<300$ $\mathrm{h} \times \mathrm{ng} / \mathrm{mL}$ (low AUC), they found that PFS was prolonged in the high AUC group compared with the low AUC group (13.8 months versus 7.4 months, respectively; $\mathrm{HR}=0.558$; $P=0.003)$. Similarly, these investigators also found prolonged OS in the high AUC group compared with the low AUC group (37.4 months versus 15.8 months, respectively; $\mathrm{HR}=0.489$; $P<0.001)$. This trial also identified a relationship between blood pressure and response to therapy. The patients that were noted to have DBP $\geq 90$ had an improved PFS compared with patients who did not (14.6 months versus 7.9 months, respectively; $\mathrm{HR}=0.590 ; P=0.006)$ and $\mathrm{OS}$ (29.5 months versus 18.5 months, respectively; $\mathrm{HR}=0.622 ; P=0.024)$. These findings opened the door to further investigation regarding the relationship between axitinib exposure and outcomes.

Dose titration was formally evaluated in a randomized Phase II study of patients with untreated metastatic RCC. ${ }^{24}$ In this trial, 213 patients received axitinib $5 \mathrm{mg}$ twice daily for 4 weeks, and the 112 patients that did not develop hypertension or significant adverse events (AEs) were randomized to titration to axitinib $10 \mathrm{mg}$ twice daily or they continued $5 \mathrm{mg}$ twice daily with placebo titration. Fifty-four percent $(95 \%$ CI: 40-67) of patients in the axitinib titration group and 34\% (95\% CI: 22-48) of patients in the placebo group had an objective response (one-sided $P=0.19$ ), while 59\% (95\% CI: 49-70) of nonrandomized patients had an objective response. There was no significant PFS difference reported between the groups (titration: 14.5 months; placebo: 15.7 months; nonrandomized: 16.6 months). The HR for PFS with axitinib titration when compared to placebo did not reach statistical significance $(\mathrm{HR}=0.85 ; 95 \% \mathrm{CI}$ : 0.54-1.35; one-sided $P=0.24$ ). AEs were similar as in other studies, ${ }^{8,13,14}$ (both 
phase II studies and the phase III study), but hypertension, hand-foot syndrome, and vomiting were more common in the axitinib titration group when compared with the placebo group. For the subset of 73 patients with pharmacokinetic sampling, the patients who were eligible for dose titration had both lower area under the plasma concentration-time curve (AUC24; $176 \mathrm{ng} \times \mathrm{h} / \mathrm{mL}$ and $187 \mathrm{ng} \times \mathrm{h} / \mathrm{mL}$ for the axitinib group and placebo group, respectively) and lower maximum observed plasma concentration at baseline (Cmax; $28.6 \mathrm{ng} / \mathrm{mL}$ and $22.5 \mathrm{ng} / \mathrm{mL}$ for the axitinib and placebo groups, respectively) when compared with the group not eligible for dose titration (AUC24 $=432 \mathrm{ng} \times \mathrm{h} / \mathrm{mL}$; $\mathrm{Cmax}=38.7$ $\mathrm{ng} / \mathrm{mL}$ ). The authors concluded that the patients eligible for dose titration likely derived clinical benefit, although the results did not reach statistical significance.

The final statement as to whether or not dose titration is useful may have come from the AXIS study. ${ }^{14}$ Selected patients appropriate for dose titration received axitinib 7 $\mathrm{mg}$ twice daily and then $10 \mathrm{mg}$ twice daily. The presentation of the data at the American Society for Clinical Oncology (ASCO) conference in 2012 did not report an improved survival rate in patients who were able to receive at least one dose escalation. ${ }^{25}$ However, when the OS analysis and updated results from the AXIS trial were presented in 2013, ${ }^{16}$ an evaluation of patients 12 weeks after the start of treatment showed that patients with a DBP $\geq 90 \mathrm{mmHg}$ had an improved OS of 20.7 months compared with 12.9 months for patients with lower blood pressure values $(\mathrm{HR}=0.716$; 95\% CI: $0.537-0.957 ; P=0.0116)$. Similar results were seen for systolic blood pressures of $\geq 140 \mathrm{mmHg}$ compared with normal systolic blood pressure, with an OS of 20.7 months compared with 17.0 months, respectively $(\mathrm{HR}=0.753$; 95\% CI: $0.556-1.019 ; P=0.0329$ ), further supporting the concept of using dose titration when indicated.

\section{Safety and tolerability of axitinib}

Axitinib is well tolerated. Published experience in the Phase II and III settings confirms a toxicity profile comparable to other agents in the class. In a Phase II study in the postcytokine population, ${ }^{8} 15$ patients $(28.8 \%)$ required dose reductions and six (11.5\%) discontinued therapy due to AEs such as hypertension, stomatitis, fatigue, diarrhea, or joint pain. The most frequent grade 3-4 toxicities were diarrhea (9.6\%), hypertension (15.4\%), and fatigue (7.7\%). Thirty (57.7\%) patients experienced any grade hypertension, of which 18 patients had a history of pre-existing hypertension. Hypertension resolved after adjusting or starting antihypertensive medications in 22 of these 30 patients. Seven of the remaining eight patients were hypertensive prior to starting therapy. Hand-foot syndrome was only noted in four $(7.7 \%)$ patients, and eleven (21.1\%) patients experienced bleeding complications, but these were predominantly epistaxis and only one (hematuria) was grade 3 . The second Phase II study, ${ }^{13}$ conducted in patients refractory to sorafenib, again suggested that the drug is generally well tolerated, as the majority of AEs were grade 1-2. The most common grade 3 AEs were hand-foot syndrome (16.1\%), fatigue (16.1\%), hypertension (16.1\%), and diarrhea (14.5\%).

The AXIS trial confirmed the overall safety profile of axitinib. ${ }^{14}$ Diarrhea, hypertension, fatigue, anorexia, nausea, and dysphonia all occurred to some degree in more than $30 \%$ of patients receiving axitinib. Hypothyroidism occurred in $19 \%$ of patients with only one grade 3 hypothyroidism event. This is important, as changes in thyroid-stimulating hormone levels appear to correlate with fatigue in patients taking axitinib. ${ }^{26}$ The most common grade 3 or greater AEs in the AXIS trial were hypertension (16\% axitinib; $11 \%$ sorafenib), fatigue (11\% axitinib; 5\% sorafenib), and diarrhea (11\% axitinib; 7\% sorafenib). ${ }^{14}$ Cutaneous toxicities were infrequent with axitinib, with only $5 \%$ of patients experiencing hand-foot syndrome (compared to $16 \%$ in the sorafenib arm) and $<1 \%$ of patients receiving axitinib reporting rash. The rates of grade 3 thrombocytopenia and neutropenia were similar for both drugs $(0 \%-1 \%)$, as was grade 3 lymphopenia (3\% for axitinib versus $4 \%$ for sorafenib). Grade 3 anemia was more common for sorafenib (4\%) compared with axitinib $(<1 \%)$. No treatment toxicity deaths were seen in the axitinib group. There were two in the sorafenib group - one due to retroperitoneal bleeding associated with tumor necrosis in a patient on anticoagulation, and the other due to gastrointestinal bleeding. It should be noted that although poorly controlled hypertension can lead to serious cardiovascular events, cardiotoxicity has rarely been reported in any of the reported axitinib studies. ${ }^{1,8,12-14,16}$ Three patients in the AXIS trial discontinued axitinib therapy due to a transient ischemic attack (TIA), while no TIAs were reported for sorafenib. ${ }^{14}$

\section{Effect of axitinib on quality of life and functional assessment}

Health-related quality of life has been assessed in various studies. In the Phase II study conducted by Rixe et al, ${ }^{8}$ axitinib responders were more likely to have diarrhea than nonresponders, but they were less likely to have deterioration in social function and global quality of life. The second Phase II study of axitinib presented by Rini et $\mathrm{al}^{13}$ evaluated patient-reported disease-related symptoms at baseline and 
after 20 weeks (day 141) of treatment. Significant adverse changes in appetite, weight, energy, and bone pain were noted, and patients reported being increasingly bothered by side effects compared to baseline. Finally, in the AXIS trial, ${ }^{14}$ quality of life was assessed as a component of a composite endpoint of the first occurrence of death, progression, or deterioration of symptoms. Axitinib was found to confer a $16 \%$ lower risk for this composite endpoint compared to sorafenib (one-sided $P=0.0203$ ). Discontinuation due to treatment-related side effects was lower with axitinib (4\% of patients; most common causes were fatigue and TIAs) compared to sorafenib ( $8 \%$ of patients; most common causes were hand-foot syndrome, diarrhea, and asthenia), which suggests better overall tolerability of axitinib compared to sorafenib. Further supporting the tolerability of axitinib was the fact that dose reduction was more frequent with sorafenib treatment (52\%) than with axitinib (31\%).

Quality of life was further evaluated within AXIS by Cella et al, ${ }^{27}$ where investigators used the Functional Assessment of Cancer Therapy (FACT) Kidney Cancer Symptom Index (FKSI), FKSI disease-related symptoms (FKSI-DRS), and the European Quality of Life self-report questionnaire (EQ-5D). This study found that the quality of life of patients on axitinib or sorafenib was similar to that of the general US population at baseline, and it was maintained until the end of treatment, when meaningful worsening of patient-reported outcomes was seen for both drugs. There was no significant difference noted in terms of quality of life for those taking axitinib and sorafenib.

\section{Axitinib in other diseases}

Axitinib is currently being evaluated as a possible treatment in multiple different settings, such as recurrent glioblastoma, melanoma, prostate cancer, pheochromocytoma/paraganglioma, hepatocellular carcinoma, nasopharyngeal, and other head and neck cancers. Thus far, it has shown promising results in a Phase II study in thyroid cancer enrolling all histologies, with $\mathrm{PR}$ in $30 \%$ of patients and SD in $38 \%$ of patients. ${ }^{28}$ Combining axitinib with traditional chemotherapy, however, has not yielded good results. In colorectal carcinoma, it was inferior to bevacizumab when given with FOLFOX (folinic acid-fluorouracil-oxaliplatin) in a Phase II study. ${ }^{29}$ In metastatic breast cancer, docetaxel with axitinib versus placebo did not result in a significantly prolonged time to progression of disease ${ }^{30}$ Gemcitabine with axitinib or placebo did not yield any significant improvement in OS in advanced pancreatic cancer. ${ }^{31}$ In lung cancer, axitinib has been compared with cisplatin and pemetrexed versus placebo for nonsquamous non- small-cell lung cancer without significant difference in PFS, the primary endpoint. ${ }^{32}$ Comparing the addition of axitinib versus bevacizumab to paclitaxel/carboplatin also yielded no significant PFS improvement for axitinib. ${ }^{33}$

\section{Future directions}

Research in regards to the effects of axitinib in the RCC setting and other select non-RCC indications is ongoing. Currently, axitinib is only approved for metastatic RCC, but further evaluation in regards to its potential neoadjuvant utility is ongoing with a Phase II trial, the Axipan study, ${ }^{34}$ which is currently active in France with results pending. Axitinib is currently being examined in the adjuvant setting to decrease the recurrence risk for high-risk RCC patients after nephrectomy (NCT01599754). It is being studied in patients with metastatic RCC unsuitable for nephrectomy (NCT01693822), and studies are ongoing for patients with nonclear cell disease, such as for those previously treated with temsirolimus (NCT01798446). Phase IB studies of axitinib with other molecularly targeted agents such as everolimus and temsirolimus have completed accrual and await presentation (NCT01334073 and NCT01529138, respectively). Combination studies with various antibodies also are underway, including a Phase IB study of axitinib and TRC105 for patients with RCC who have progressed on prior therapy. TRC105 is an antibody to CD105, which is an angiogenesis pathway target on ECs that is distinct from VEGFR (NCT01806064). Finally, axitinib also is being examined in advanced RCC in combination with inhibitors of the PD-1/PD-L1 axis, such as pembrolizumab (MK-3475, a PD-1 inhibitor) (NCT02133742).

\section{Conclusion}

As a highly potent inhibitor of the VEGF-VEGFR signaling axis that is tolerable, axitinib has emerged as an important therapeutic option for use in the treatment of patients with refractory metastatic clear cell RCC. Axitinib has been found to confer clear-cut benefits to patients in terms of prolonging the PFS in the second-line setting over sorafenib. Its toxicity profile is no worse than that of other drugs in its class, and a useful strategy that may enhance clinical benefit has been developed to increase the dose in the absence of treatmentrelated AEs. Because of the choice of sorafenib as a comparator in the AXIS study, questions remain regarding axitinib's place in the treatment of patients with refractory disease relative to everolimus that likely will remain unanswered. Additionally, because the randomized first-line study was underpowered, questions remain as to whether there is a 
place for axitinib in the first-line setting. In the end, axitinib makes an important and useful contribution to management in second-line metastatic clear cell RCC for use when VEGFR-inhibitor therapy is desired, and the potential exists for greater utility in the future as a combination partner with emerging novel therapies, such as with targeted immunomodulatory agents.

\section{Disclosure}

The authors report no conflicts of interest in this work.

\section{References}

1. Rugo HS, Herbst RS, Liu G, et al. Phase I trial of the oral antiangiogenesis agent AG-013736 in patients with advanced solid tumors: pharmacokinetic and clinical results. J Clin Oncol. 2005;23(24): 5474-5483.

2. Inai T, Mancuso M, Hashizume H, et al. Inhibition of vascular endothelial growth factor (VEGF) signaling in cancer causes loss of endothelial fenestrations, regression of tumor vessels, and appearance of basement membrane ghosts. Am J Pathol. 2004;165(1):35-52.

3. Hu-Lowe DD, Zou HY, Grazzini ML, et al. Nonclinical antiangiogenesis and antitumor activities of axitinib (AG-013736), an oral, potent, and selective inhibitor of vascular endothelial growth factor receptor tyrosine kinases 1, 2, 3. Clin Cancer Res. 2008;14(22): 7272-7283.

4. Mendel DB, Laird AD, Xin X, et al. In vivo antitumor activity of SU11248, a novel tyrosine kinase inhibitor targeting vascular endothelial growth factor and platelet-derived growth factor receptors: determination of a pharmacokinetic/pharmacodynamic relationship. Clin Cancer Res. 2003;9(1):327-337.

5. Kumar R, Knick VB, Rudolph SK, et al. Pharmacokineticpharmacodynamic correlation from mouse to human with pazopanib, a multikinase angiogenesis inhibitor with potent antitumor and antiangiogenic activity. Mol Cancer Ther. 2007;6(7):2012-2021.

6. Ahmad T, Eisen T. Kinase inhibition with BAY 43-9006 in renal cell carcinoma. Clin Cancer Res. 2004;10(18 Pt 2):6388S-6392S.

7. Tortorici MA, Toh M, Rahavendran SV, et al. Influence of mild and moderate hepatic impairment on axitinib pharmacokinetics. Invest New Drugs. 2011;29(6):1370-1380.

8. Rixe O, Bukowski RM, Michaelson MD, et al. Axitinib treatment in patients with cytokine-refractory metastatic renal-cell cancer: a phase II study. Lancet Oncol. 2007;8(11):975-984.

9. Motzer RJ, Bacik J, Murphy BA, Russo P, Mazumdar M. Interferon-alfa as a comparative treatment for clinical trials of new therapies against advanced renal cell carcinoma. J Clin Oncol. 2002;20(1):289-296.

10. Escudier B, Roigas J, Gillessen S, et al. Phase II study of sunitinib administered in a continuous once-daily dosing regimen in patients with cytokine-refractory metastatic renal cell carcinoma. J Clin Oncol. 2009;27(25):4068-4075.

11. Hutson TE, Davis ID, Machiels JH, et al. Biomarker analysis and final efficacy and safety results of a phase II renal cell carcinoma trial with pazopanib (GW786034), a multi-kinase angiogenesis inhibitor [abstract]. J Clin Oncol. 2008;26(15S Suppl):abstract 5046.

12. Rini BI, de La Motte Rouge T, Harzstark AL, et al. Five-year survival in patients with cytokine-refractory metastatic renal cell carcinoma treated with axitinib. Clin Genitourin Cancer. 2013;11(2):107-114.

13. Rini BI, Wilding G, Hudes G, et al. Phase II study of axitinib in sorafenib-refractory metastatic renal cell carcinoma. J Clin Oncol. 2009;27(27):4462-4468.

14. Rini BI, Escudier B, Tomczak P, et al. Comparative effectiveness of axitinib versus sorafenib in advanced renal cell carcinoma (AXIS): a randomised phase 3 trial. Lancet. 2011;378(9807):1931-1939.
15. United States Food and Drug Administration [webpage on the Internet]. Axitinib. Silver Spring, MD: US Food and Drug Administration; 2012. Available from: http://www.fda.gov/Drugs/InformationOnDrugs/ ApprovedDrugs/ucm289439.htm. Accessed February 22, 2014.

16. Motzer RJ, Escudier B, Tomczak P, et al. Axitinib versus sorafenib as second-line treatment for advanced renal cell carcinoma: overall survival analysis and updated results from a randomised phase 3 trial. Lancet Oncol. 2013;14(6):552-562.

17. Hotte SJ, Bjarnason GA, Heng DY, et al. Progression-free survival as a clinical trial endpoint in advanced renal cell carcinoma. Curr Oncol. 2011;18 Suppl 2:S11-S19.

18. Hutson TE, Lesovoy V, Al-Shukri S, et al. Axitinib versus sorafenib as first-line therapy in patients with metastatic renal-cell carcinoma: a randomised open-label phase 3 trial. Lancet Oncol. 2013;14(13): 1287-1294.

19. Karam JA, Devine CE, Urbauer DL, et al. Phase 2 trial of neoadjuvant axitinib in patients with locally advanced nonmetastatic clear cell renal cell carcinoma. Eur Urol. Epub February 7, 2014.

20. Rini BI, Schiller JH, Fruehauf JP, et al. Diastolic blood pressure as a biomarker of axitinib efficacy in solid tumors. Clin Cancer Res. 2011;17(11):3841-3849.

21. Jonasch E, Bair A, Chen Y, Rini BI. Axitinib with or without dose titration as first-line therapy for metastatic renal cell carcinoma (mRCC) [abstract]. J Clin Oncol. 2010;28(Suppl 15S):abstract TPS235.

22. Rini BI, Garrett M, Poland B, et al. Axitinib in metastatic renal cell carcinoma: results of a pharmacokinetic and pharmacodynamic analysis. J Clin Pharmacol. 2013;53(5):491-504.

23. Qi WX, He AN, Shen Z, Yao Y. Incidence and risk of hypertension with a novel multi-targeted kinase inhibitor axitinib in cancer patients: a systematic review and meta-analysis. Br J Clin Pharmacol. 2013; 76(3):348-357.

24. Rini BI, Melichar B, Ueda T, et al. Axitinib with or without dose titration for first-line metastatic renal-cell carcinoma: a randomised double-blind phase 2 trial. Lancet Oncol. 2013;14(12):1233-1242.

25. Rini BI, Escudier BJ, Michaelson MD, et al. Phase III AXIS trial for second-line metastatic renal cell carcinoma (mRCC): effect of prior first-line treatment duration and axitinib dose titration on axitinib efficacy [abstract]. J Clin Oncol. 2012;30 Suppl 5:abstract 354.

26. Mukohara T, Nakajima H, Mukai H, et al. Effect of axitinib (AG-013736) on fatigue, thyroid-stimulating hormone, and biomarkers: a phase I study in Japanese patients. Cancer Sci. 2010; 101(4):963-968.

27. Cella D, Escudier B, Rini B, et al. Patient-reported outcomes for axitinib vs sorafenib in metastatic renal cell carcinoma: phase III (AXIS) trial. Br J Cancer. 2013;108(8):1571-1578.

28. Cohen EE, Rosen LS, Vokes EE, et al. Axitinib is an active treatment for all histologic subtypes of advanced thyroid cancer: results from a phase II study. J Clin Oncol. 2008;26(29):4708-4713.

29. Infante JR, Reid TR, Cohn AL, et al. Axitinib and/or bevacizumab with modified FOLFOX-6 as first-line therapy for metastatic colorectal cancer: a randomized phase 2 study. Cancer. 2013;119(14): 2555-2563.

30. Rugo HS, Stopeck AT, Joy AA, et al. Randomized, placebo-controlled, double-blind, phase II study of axitinib plus docetaxel versus docetaxel plus placebo in patients with metastatic breast cancer. J Clin Oncol. 2011;29(18):2459-2465.

31. Kindler HL, Ioka T, Richel DJ, et al. Axitinib plus gemcitabine versus placebo plus gemcitabine in patients with advanced pancreatic adenocarcinoma: a double-blind randomised phase 3 study. Lancet Oncol. 2011;12(3):256-262.

32. Belani CP, Yamamoto N, Bondarenko IM, et al. Randomized phase II study of pemetrexed/cisplatin with or without axitinib for non-squamous non-small-cell lung cancer. BMC Cancer. 2014;14:290.

33. Twelves C, Chmielowska E, Havel L, et al. Randomised phase II study of axitinib or bevacizumab combined with paclitaxel/carboplatin as first-line therapy for patients with advanced non-small-cell lung cancer. Ann Oncol. 2014;25(1):132-138. 
34. Les essais cliniques. Registre des essais cliniques français en cancérologie [Clinical trials. Register of French cancer clinical trials] [webpage on the Internet]. Paris: Insitut National Du Cancer; 2014. Available from: http://www.e-cancer.fr/en/recherche/rechercheclinique/registre-des-essais-cliniques/registre-des-essais-cliniques/ details-etude?idFiche=2256. Accessed January 5, 2015. French.

35. Escudier B, Pluzanska A, Koralewski P, et al; AVOREN Trial investigators. Bevacizumab plus interferon alfa-2a for treatment of metastatic renal cell carcinoma: a randomised, double-blind phase III trial. Lancet. 2007;370(9605):2103-2111.

36. Escudier BJ, Bellmunt J, Negrier S, et al. Final results of the phase III randomized, double-blind AVOREN trial of first-line bevacizumab $(\mathrm{BEV})+$ interferon-a2a (IFN) in metastatic renal cell carcinoma (mRCC) [abstract]. J Clin Oncol. 2009;27(15 Suppl):abstract 5020.

37. Escudier B, Bellmunt J, Négrier S, et al. Phase III trial of bevacizumab plus interferon alfa-2a in patients with metastatic renal cell carcinoma (AVOREN): final analysis of overall survival. J Clin Oncol. 2010; 28(13):2144-2150.

38. Rini BI, Halabi S, Rosenberg JE, et al. Bevacizumab plus interferon alfa compared with interferon alfa monotherapy in patients with metastatic renal cell carcinoma: CALGB 90206. J Clin Oncol. 2008;26(33): 5422-5428.

39. Rini BI, Halabi S, Rosenberg JE, et al. Phase III trial of bevacizumab plus interferon alfa versus interferon alfa monotherapy in patients with metastatic renal cell carcinoma: final results of CALGB 90206. J Clin Oncol. 2010;28(13):2137-2143.

40. Hudes G, Carducci M, Tomczak P, et al; Global ARCC Trial. Temsirolimus, interferon alfa, or both for advanced renal-cell carcinoma. N Engl J Med. 2007;356(22):2271-2281.
41. Motzer RJ, Escudier B, Oudard S, et al; RECORD-1 Study Group. Efficacy of everolimus in advanced renal cell carcinoma: a double-blind, randomised, placebo-controlled phase III trial. Lancet. 2008;372(9637): 449-456.

42. Motzer RJ, Escudier B, Oudard S, et al; RECORD-1 Study Group. Phase 3 trial of everolimus for metastatic renal cell carcinoma: final results and analysis of prognostic factors. Cancer. 2010;116(18): 4256-4265.

43. Escudier B, Eisen T, Stadler WM, et al; TARGET Study Group. Sorafenib in advanced clear-cell renal-cell carcinoma. $N$ Engl J Med. 2007;356(2):125-134.

44. Escudier B, Eisen T, Stadler WM, et al. Sorafenib for treatment of renal cell carcinoma: Final efficacy and safety results of the phase III treatment approaches in renal cancer global evaluation trial. J Clin Oncol. 2009;27(20):3312-3318.

45. Motzer RJ, Hutson TE, Tomczak P, et al. Sunitinib versus interferon alfa in metastatic renal-cell carcinoma. $N$ Engl J Med. 2007;356(2): $115-124$.

46. Motzer RJ, Hutson TE, Tomczak P, et al. Overall survival and updated results for sunitinib compared with interferon alfa in patients with metastatic renal cell carcinoma. J Clin Oncol. 2009;27(22): 3584-3590.

47. Sternberg CN, Davis ID, Mardiak J, et al. Pazopanib in locally advanced or metastatic renal cell carcinoma: results of a randomized phase III trial. J Clin Oncol. 2010;28(6):1061-1068.

48. Sternberg CN, Hawkins RE, Wagstaff J, et al. A randomised, doubleblind phase III study of pazopanib in patients with advanced and/or metastatic renal cell carcinoma: final overall survival results and safety update. Eur J Cancer. 2013;49(6):1287-1296.
Cancer Management and Research

\section{Publish your work in this journal}

Cancer Management and Research is an international, peer-reviewed open access journal focusing on cancer research and the optimal use of preventative and integrated treatment interventions to achieve improved outcomes, enhanced survival and quality of life for the cancer patient The journal welcomes original research, clinical \& epidemiological

\section{Dovepress}

studies, reviews \& evaluations, guidelines, expert opinion \& commentary, case reports \& extended reports. The manuscript management system is completely online and includes a very quick and fair peerreview system, which is all easy to use. Visit http://www.dovepress.com/ testimonials.php to read real quotes from published authors. 